\title{
How to become an anaesthetist
}

\author{
Jacqui Wise
}

London, UK

A career in anaesthesia is rewarding and challenging. Anaesthetists form the largest specialty group of doctors in the NHS and their skills are used in all aspects of patient care. They provide care to patients across all age ranges and a spectrum of comorbidities, and work in many different areas of the hospital.

The first step to becoming an anaesthetist is completing five years of undergraduate medical training, followed by two years of foundation training. During the second year of foundation training, trainees can apply for postgraduate training in anaesthesia.

There are two options for postgraduate training. One is the direct route through core training, which takes a total of seven years. The other is an eight year anaesthesia programme, which includes two years of the acute care common stem (ACCS) programme.

The ACCS programme covers the specialties of anaesthesia, acute medicine (general internal), emergency medicine, and intensive care medicine. The anaesthesia component in the ACCS programme is nearly identical to the first six months of the core anaesthetics programme. Trainees also have the option of completing dual certificates of completion of training in anaesthesia and intensive care medicine, which normally takes eight and a half years to complete (www.rcoa.ac.uk/intensivecare-medicine/dual-training-icm-and-anaesthesia).

\section{Stages of training}

There are four phases of training.

\section{Basic level}

This takes two years if on the core training programme or three years on the ACCS programme. It includes an introduction to anaesthesia which is usually completed within the first three to six months.

Trainees will need to pass the initial assessment of competence (IAC) at the end of this period to show they have a basic understanding of anaesthesia. They can then be added to the on-call rota although trainees will still be under the supervision of a named consultant. In order to pass the IAC, trainees will have to complete a minimum of 19 separate assessments.

The Royal College of Anaesthetists has produced an online guide to support trainees through the first three to six months of training, it includes learning resources and useful documents (www.e-lfh.org.uk/e-learning-sessions/rcoa-novice/home.html). Once trainees have completed the IAC they can start working on the other units. These are:
- Critical incidents

Day surgery

- General, urological, and gynaecological surgery

- Head, neck, maxillofacial, and dental surgery

- Non-theatre (anaesthesia for diagnostic imaging)

- Orthopaedic surgery

- Paediatrics

- Child protection

- Pain medicine

- Perioperative medicine

Regional

- Sedation

- Intensive care medicine

- Transfer medicine

Trauma and stabilisation

Obstetric anaesthesia.

\section{Intermediate level}

This takes two years and introduces trainees to specialist areas of anaesthesia, such as cardiothoracic anaesthesia and neuroanaesthesia. Trainees may take optional units in ophthalmic, plastics and burns, and vascular surgery.

During this phase, trainees must pass the final Fellowship of the Royal College of Anaesthetists examination. This written exam is held twice a year in September and March at a number of venues across the UK. It consists of a three hour multiple choice exam followed by a three hour paper with constructed response questions.

The 90 multiple choice questions aim to test factual knowledge and the constructed response questions aim to test judgment, ability to prioritise and summarise, and capability to present an argument clearly and succinctly.

The 12 constructed response questions will contain one question from each of the mandatory units of training and six from general duties which may include a maximum of one question from the optional units of training. Trainees have a maximum of six attempts and a pass is valid for three years. 


\section{Higher level}

This level of training takes two years and is called post fellowship training. At least one year must be done in general duties and essential units that must be covered include airway management, perioperative medicine, and management of respiratory and cardiac arrest. There are also optional units in pain medicine, ophthalmic, plastics and burns, anaesthesia in developing countries, conscious sedation in dentistry, military anaesthesia, and remote and rural anaesthesia.

\section{Advanced level}

This is one year in duration. In order to prepare the trainee for consultant practice the learning is focused on building expertise in a chosen area and developing skills in leadership, team working, and management. Those trainees who want to practise in a tertiary referral centre may want to specialise in neuroanaestheisa, cardiothoracic anaesthesia, or paediatric anaesthesia. Those who want to follow a more generalist career in a district general hospital will complete one year of general duties.

Towards the end of the training programme, trainees undergo a final summative assessment and, if successful, will be given a recommendation for completion of training by their postgraduate dean. When a trainee is within six months of their completion date they should submit the college notification of completion of training form (www.rcoa.ac.uk/training-and-thetraining-programme/completion-of-training-and-cctcesrcp). The General Medical Council will then contact the trainee asking them to complete the online application and they will be added to the specialist register.

\section{Skills needed}

Anaesthetists need to have good team skills as they will work with many different specialties. In their role, anaesthetists use a lot of equipment to monitor heart rate, blood pressure, and breathing and need to be dextrous and organised. They also need an advanced understanding of basic science plus good maths skills to calculate doses.

Trainee anaesthetists will also need excellent communication skills as an important part of their role is talking to patients and relatives, who may be feeling anxious, about their procedure. Anaesthetists also need to work well under pressure; they should be able to make calm decisions in a sometimes stressful environment. 